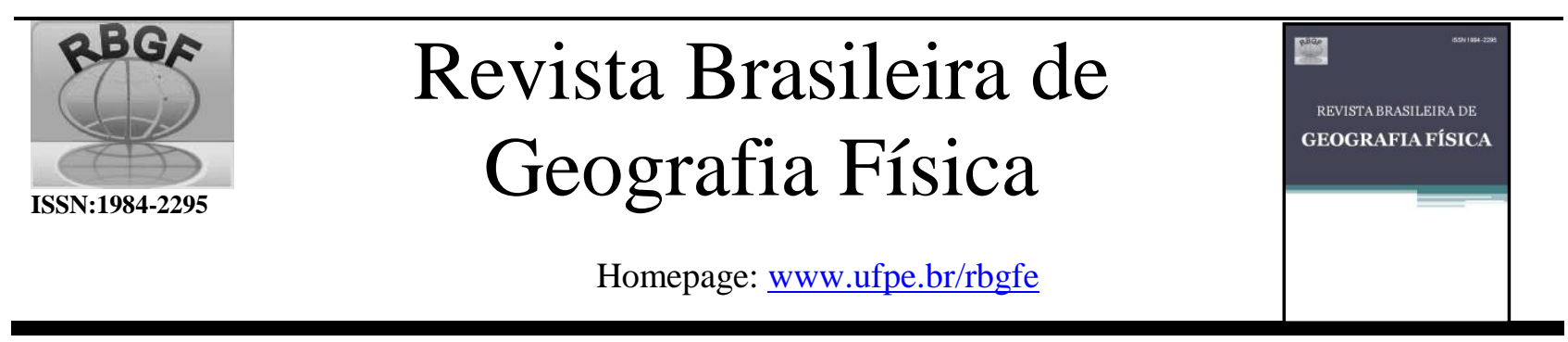

\title{
Avaliação Interanual das Anomalias de Chuvas da Bacia Hidrográfica do Rio Mundaú - Ceará
}

Flávio Teixeira Nunes. Professor de Geografia Física - Secretaria de Educação do Estado do Ceará - SEDUC. Flavio.tn10@Yahoo.com.br Francisco das Chagas Vasconcelos Júnior. Pesquisador da Fundação Cearense de Meteorologia e Recursos Hídricos - FUNCEME. juniorphy@gmail.com Cleiton da Silva Silveira. Professor Universidade da Integração Internacional da Lusofonia Afro-Brasileira - UNILAB. cleitonsilveira@ unilab.edu.br

Artigo recebido em 27/05/2018 e aceito em 09/01/2019

\section{R E S U M O}

Este trabalho avalia a variabilidade temporal e espacial das precipitações da Bacia Hidrográfica do Rio Mundaú - Ceará, investigando relações entre as alterações climáticas em curso na escala mundial, e possíveis alterações em escala regional e suas consequências na hidrologia local. Para a realização deste trabalho, foram analisadas séries históricas de precipitações dos postos pluviométricos da FUNCEME localizados nas proximidades da serra de Itapipoca, sertão e na região costeira ao longo da bacia no período de 1976 a 2017. Foram feitas análises estatísticas para obtenção das médias e do desvio padrão, além da realização de testes de tendências e correlação. O comportamento pluviométrico ao longo do tempo foi analisado através do método IAC - Índice de Anomalias de Chuvas, possibilitando a identificação de período com anomalias de positivas e períodos com anomalias negativas, além da relação destas anomalias com as oscilações de temperatura do Oceano Pacífico central. A análise do IAC mostra uma leve predominância de anomalias negativas de chuvas na área da bacia, com ciclos de anos secos e anos úmidos, sendo o último período de 2012 a 2016 o período seco mais prolongado da série, mesmo assim não se identifica alteração consistente no clima regional na série estudada. Dois dos quatro postos analisados apresentaram tendências negativas de precipitações, contudo a média geral da bacia as tendências foram próximas de zero. Foi observado aumento de anomalias negativas de chuvas em todos os postos e uma significativa relação de anomalias negativas de chuvas com o fenômeno ENOS.

Palavras Chaves - Clima, Rio Mundaú, precipitação.

\section{Interannual Evaluation of Rainfall Anomalies in the Mundaú River Basin - Ceará}

\section{A B S T R A C T}

This work evaluates the temporal-spatial variability of the rainfall in the Mundaú River basin - Ceará, seeking for relationships between ongoing climate changes on a global scale and possible changes in regional scale and its affects in the local hydrometeorology. For the accomplishment of this work, historical data series of precipitations from raingauge stations of the FUNCEME located in the vinicity of the mountain of Itapipoca, Sertão and in the coastal region along the valley of the Mundaú River basin were analyzed from 1976 to 2017. Statistical analysis was performed to obtain the means and the standard deviations, in addition to performing trend and correlation tests. The rainfall variability over time was analyzed through the IAC - Rainfall Anomalies Index, allowing the identification of the period with positive anomalies with Sea Surface Temperature in central Pacific Ocean. The IAC show a slight predominance of negative rainfall anomalies, with cycles of dry years and wet years, the last dry period covered 2012 to 2016 being the longest dry period of the historical record, even though no consistent changes are identified in the local climate from the time series studied. Two of the four stations analyzed presented negative trends, but the overall basin mean had almost zero trend. It was observed increase of negative anomalies in all the stations and a significant relation of negative anomalies during warm phase of the ENSO.

keywords - Climate, Mundaú River, precipitation

\section{Introdução}

O aprofundamento sobre os estudos acerca das mudanças climáticas e suas consequências tem ganhado cada vez mais destaque tanto no meio acadêmico e científico quanto na mídia. Tudo isso ocorre pelo fato dos fenômenos climáticos associados ao aquecimento do planeta terem se intensificado bastante, sobretudo com o limiar das duas primeiras décadas do século XXI. Segundo (Freitas e Soitos, 2014) com o aquecimento

Nunes, F. T., Vasconcelos Júnior, F. C., Silveira, C. S. 
adicional do planeta, haverá alterações no ciclo hidrológico e com isso o regime de disponibilidade de água para as atividades humanas será alterado, acarretando prejuízos múltiplos tanto para as atividades econômicas quanto para a manutenção dos ecossistemas em todo mundo. $\mathrm{O}$ quinto Relatório (IPCC, 2014) apresentou fortes evidências de que as mudanças do clima podem afetar drasticamente o planeta, principalmente no que se refere a extremos climáticos, (Silva et al., 2017).

De acordo com o Intergorvenmental Panel on Climate Change (IPCC, 2007) as mudanças climáticas são variações estatisticamente significativas em parâmetros climáticos médios, que ocorrem a nível global e refletem a nível regional, essas variações são comprovadas cientificamente e observadas ao longo de décadas de pesquisas. Nas últimas décadas as mudanças climáticas têm causado impactos sobre os sistemas naturais e humanos em todos os continentes e através dos oceanos (IPCC, 2014). As variações estão relacionadas à frequência e intensidade de eventos climáticos extremos, sendo que as características marcantes destas alterações no clima é o aumento da frequência com que eventos de secas e tempestades extremas, furacões e ondas de frio e de calor, dentre outros, estão acontecendo nos últimos anos. Para (Marengo, 2017) a grande concentração de $\mathrm{CO} 2$ na atmosfera lançado através das atividades humana como a queima de combustíveis fósseis e mudanças no uso da terra é um dos principais causadores do aquecimento do planeta.

Os gases do efeito estufa existem naturalmente na atmosfera, mais nas últimas cinco décadas a concentração de $\mathrm{CO} 2$ aumentou drasticamente em decorrência da queima de combustíveis fósseis, do desmatamento e das queimadas, comprometendo assim o equilíbrio climático do planeta (Leandro, 2013), fato este revalidado pelos estudos do IPCC. De acordo com uma matéria do Jornal El País de 18 de janeiro de 2018, a última década e os anos de 2014, 2015 e 2016 foram os mais quentes da história desde o início das medições.

Diante das mudanças climáticas o Nordeste Brasileiro (NEB) é uma das regiões que apresenta um alto grau de vulnerabilidade às secas extremas, (Travassos et al., 2013). Projeções do Painel Brasileiro de Mudanças Climáticas (PBMC, 2014) indicam que a partir de 2070 a condições de temperatura para o NEB apresentarão elevação entre $3,5^{\circ}$ e $4,5^{\circ} \mathrm{C}$ e um agravamento do déficit hídrico com diminuição na distribuição das chuvas entre 40 e $50 \%$, podendo desencadear a partir dai um processo de desertificação da caatinga. Não bastasse a já conhecida vulnerabilidade natural à escassez de chuva. O último relatório do IPCC apresenta como um consenso dos pesquisadores, a expectativa de redução de chuvas para o NEB a partir da segunda metade para o final do Sec. XXI. Tanto o AR4 quanto o AR5 consideram que para a segunda metade deste século a quantidade de modelos climáticos que apontam para essa redução, aumenta consideravelmente. Estes relatórios indicam para o semiárido nordestino, um aumento de temperatura de 3 a $5,5^{\circ} \mathrm{C}$ até o final deste século. Avaliando os piores dos cenários as consequências dessa elevação da temperatura será o aumento dos períodos de seca com drástica redução na produção de alimentos, pela diminuição da agricultura de subsistência na região (Cunningham et al., 2017).

Como a maioria das culturas agrícolas do Nordeste depende exclusivamente da regularidade das chuvas, o monitoramento das anomalias de chuvas e sua variabilidade espacial e temporal são de fundamental importância para o planejamento, tanto para o planejamento agrícola quanto para o abastecimento de água nas grandes cidades (Assis et al., 2015).

As duas primeiras décadas do século XXI se caracterizam por extremos climáticos que geraram de forma quase sincronizadas uma série de desastres naturais pelo Brasil tais como: secas no Nordeste Brasileiro de 2010 a 2016, secas no Sudeste em 2014 e 2015, secas na Amazônia em 2005, 2010 e 2016 (Marengo, 2017). O NEB experimentou a partir de 2010 um dos mais longos períodos de secas extremas em comparação há décadas anteriores.

Com a tendência de redução de chuvas no Nordeste um dos grandes problemas é o efeito causado na disponibilidade de água (Soares e Campos, 2013). Especialistas mostram que a crise da água está ocorrendo devido ao mau gerenciamento, no entanto para outros pesquisadores, não é apenas a questão do gerenciamento, envolve problemas ambientas, agravados pelo modelo econômicos e seu desenvolvimento (Olivo e Ishiki, 2014). Existem dois tipos de escassez de água: a escassez econômica quando não há investimento em infraestrutura hídrica e manutenção ambiental, e a escassez física quantitativa, cerca de um bilhão de pessoas no mundo vive em bacias hidrográficas com escassez econômica de água (Cirilo 2015).

De acordo com estudos existe uma estreita relação entre as anomalias de temperatura do Oceano Pacífico leste e central e o fenômeno das secas no NEB. Secas severas e períodos de grande 
umidade no NEB são associados aos padrões anormais de circulação atmosférica global de grande escala associado ao El Nino Oscilação Sul - ENOS (Nobrega e Santiago, 2014). Vários estudos mostram que a região tende a receber anomalias negativas de chuvas durante os episódios de El Nino, e anomalias positivas durante a ocorrência do La Nina. Além do ENOS, de acordo com (Alves et al., 2016), outros fenômenos como o gradiente de Temperatura da Superfície do Mar (TSM) do Atlântico Tropical (Dipolo do Atlântico) o qual modula o deslocamento anômalo anual da Zona de Convergência Intertropical (ZCIT) também é responsável pelas precipitações no NEB. Se tratando do Dipolo do Attântico, estudo realizado por (Nobrega et al., 2015) apontou que ambos os eventos atuando de forma isolada e exercem influências nas precipitações do NEB, mas quando os dois fenômenos atuam de forma conjunta a influência é bem mais acentuada, alterando o comportamento do escoamento atmosférico em baixos e altos níveis na vinicidade do Nordeste Brasileiro, contudo o ENSO é um modulador de grande escala sendo e tem maior efeito e previsibilidade do que o Dipolo.

Diante das perspectivas de eventos de secas extremas e redução de chuvas para o Semiárido Brasileiro este trabalho tem como objetivo analisar a variabilidade temporal e espacial nas anomalias de chuvas na Bacia Hidrográfica do Rio Mundaú Ceará, além de suas relações com os eventos El Nino e La Nina como fenômenos moduladores da precipitação no NEB através do índice IAC, Índice de Anomalias de Chuva, verificando assim se existe tendências pluviométricas significativas dentro da série histórica estudada, de forma a melhorar a

\section{Material e métodos}

Caracterização da Área de Estudos

O Rio Mundaú nasce na Serra de Uruburetama aproximadamente a $3^{\circ} 37^{\prime} 32^{\prime} \mathrm{S}$ e $39^{\circ} 33^{\prime} 42^{\prime \prime} \mathrm{W}$, sua bacia se estende a partir deste município, ocupando terras dos municípios de Tururu, Itapipoca e Trairi, Figura 1. Em seu trajeto percorre cerca de 97,6 km até seu encontro com o Oceano Atlântico na divisa dos Municípios de Itapipoca e Trairi, Litoral Norte do estado do Ceará de acordo com a Secretaria de Recursos Hídricos do Ceará (SRH). O relatório da SRH considera que a Bacia do Mundaú é composta pela união dos Rios Mundaú e Cruxati já bem próximo da sua foz, no entanto, para efeito deste estudo e levando em conta que a junção dos dois rios disponibilidade de dados e a organização das informações para uma melhor articulação que vise aperfeiçoar a gestão dos recursos hídricos na bacia hidrográfica, e uma melhor adaptabilidade ao fenômeno da seca (Marengo, 2016).

Ao analisarem as precipitações pluviométricas do município de Castelo do Piauí através do IAC, (Santos e Aquino, 2017) visualizaram a ocorrência de anos mais secos e anos mais chuvosos, os resultados apontam que anomalias negativas e positivas de chuvas são influenciadas pela ocorrência do El Nino e do La Nina, bem como com as fases negativas e positivas do Dipolo do Atlântico.

O IAC além de ser de fácil aplicabilidade se constitui como um método eficiente para avaliar a intensidade de eventos extremos de precipitações sejam eventos negativos ou positivos (Gross e Cassol, 2015). Já (Chechi e Sanches, 2013) utilizaram o método do IAC para avaliar a relação das anomalias de chuvas com o fenômeno ENOS na região do alto Uruguai gaúcho, verificando que a maioria dos anos de El Nino teve uma relação com as precipitações da região.

Este artigo foi estruturado da seguinte forma: na seção de Material e Métodos é descrito a área de estudo e a forma de como os dados foram observados foram utilizados nesse trabalho. $\mathrm{Na}$ seção seguinte de Resultados da Discussão são mostrados através de gráficos e tabelas os principais resultados sobre os testes de tendências e correlação utilizados no trabalho, bem como as anomalias de chuvas e suas relações com o fenômeno ENOS. Na seção de Conclusões são apresentados os principais achados acerca da pluviosidade da Região da Bacia do Rio Mundaú.

acontece bem próxima da foz, consideram-se apenas as terras banhadas pelo Rio Mundaú.

A bacia estudada neste trabalho faz parte da Bacia do Litoral, uma das unidades hidrográfica classificada de acordo com o Plano Estadual dos Recursos Hídricos do Estado do Ceará. A Bacia do Litoral está localizada entre as bacias do Rio Curu e a Bacia do Ria Acaraú, apresentando uma área de drenagem de $8.472 \mathrm{~km}^{2}$, a mesma ocupa 6\% do território cearense (COGERH, 2016), e é formada pela junção de três bacias independentes, sendo elas a Bacia do Rio Aracatiassu, a Bacia do Aracati-Mirim e a Bacia do Rio Mundaú. Por sua vez a Bacia Hidrográfica do Rio Mundaú ocupa uma área de aproximadamente $985 \mathrm{~km}^{2}$, sua localização geográfica se encontra entre as coordenadas $03^{\circ}$ 
09' $14^{\prime \prime}$ ' e $03^{\circ} 39^{\prime} 52^{\prime \prime}$ ' de latitude sul e $39^{\circ} 20^{\prime} 33^{\prime \prime}$

e $39^{\circ} 36^{\prime} 34^{\prime \prime}$ ' de longitude oeste.

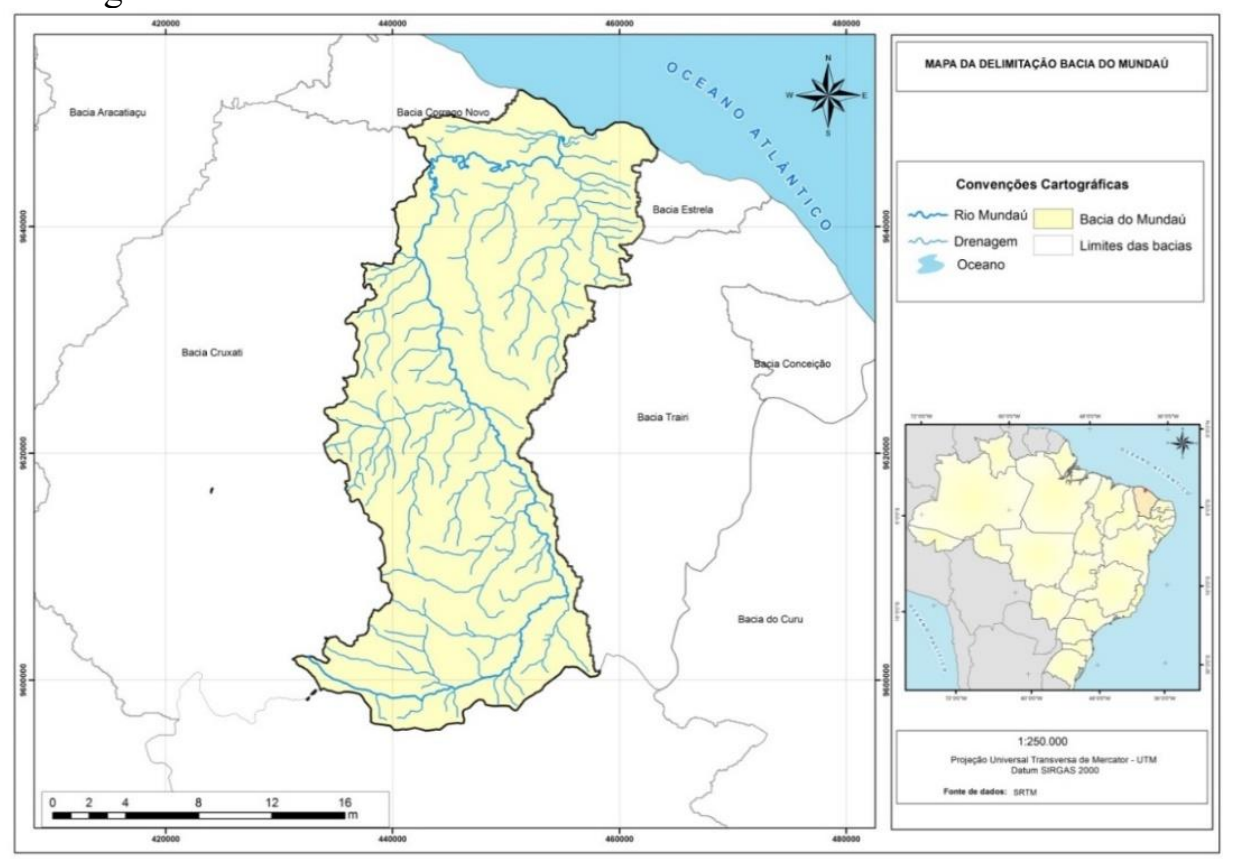

Figura 1 - Delimitação da Bacia Hidrográfica do Rio Mundaú - Ce.

Método e Dados

Para (Sanches et al., 2014) o uso IAC em análise de séries temporais de precipitações tem se mostrados uma importante ferramenta de análise, tanto em virtude de sua simplicidade funcional como também pela possibilidade de determinar anomalias quantitativas e qualitativas de precipitações.

Para avaliação do IAC foi seguido a metodologia proposta e utilizada por (Sanches et al., 2014; Noronha et al., 2015), cada ano foi classificado de acordo com intensidade de umidade e/ou severidade de escassez de chuva, de acordo com a (Tabela 1).

Tabela 1 - Classificação da umidade segundo IAC.

\begin{tabular}{ll}
\hline Índice de Anomalias de Chuvas - IAC & $\begin{array}{l}\text { Classificação da pluviosidade de acorde } \\
\text { com o IAC }\end{array}$ \\
\hline IAC maior que 4 & Ano extremamente úmido (EU) \\
$\mathbf{2}<$ IAC $\leq \mathbf{4}$ & Ano muito úmido (MU) \\
$\mathbf{0}<$ IAC $\leq \mathbf{2}$ & Ano úmido (U) \\
IAC $=\mathbf{0}$ & Nem seco nem úmido \\
$\mathbf{0}>$ IAC $\geq \mathbf{- 2}$ & Seco (S) \\
$\mathbf{- 2}>$ IAC $\geq \mathbf{- 4}$ & Muito seco (MS) \\
\hline IAC menor que $-\mathbf{4}$ & Extremamente seco (ES) \\
\hline
\end{tabular}

\section{Dados Pluviométricos}

Para a coleta de dados climatológicos foi utilizado como referência orientações da World Meteorological Organization (WMO) que recomenda o cálculo das normais de 30 anos para séries climáticas como, por exemplo, para período de início de 1901 a 1930 e dando continuidade com períodos sucessivos de 30 anos, como de 1931 a 1960, 1961 a 1990 e assim por diante.

Os dados históricos de precipitações foram obtidos a partir dos quatro postos pluviométricos monitorados e disponibilizados pela Fundação Cearense de Meteorologia e Recursos Hídricos (FUNCEME, 2016) dentro da Bacia Hidrográfica do Rio Mundaú e em suas proximidades de acordo com a (tabela 2). Os 
mesmos foram selecionados de acordo com a consistência, tempo de fornecimento de dados contemplando 42 anos de registros utilizados na série histórica utilizada, que apresentaram poucas falhas e tenha uma importância estratégica para o aporte hidrológico da bacia hidrográfica em análise.

Mesmo havendo uma significativa rede de postos pluviométricos na área da bacia hidrográfica em estudo, foi verificado que vários deles não se encontravam em atividade ou apresentaram falhas que comprometiam a utilização dos dados nos resultados da pesquisa, desta forma, verificou-se que apenas quatro postos pluviométricos tinham dados consistentes e de período significativo para serem utilizados (Santos e Ferreira, 2016), sendo dois na área de abrangência da bacia hidrográfica, e outros dois em sua proximidade. Dessa forma foram utilizadas séries históricas para avaliação da variabilidade de chuvas a partir dos postos pluviométricos descritos de acordo com a (tabela 2).

O posto localizado em Itapipoca localizase na sede do Município na subida da serra de Uruburetama, por se localizar na área de barlavento é bem servido de chuvas provenientes do litoral que alimentam uma importante rede hídrica, mantendo os reservatórios da região bem abastecidos mesmo em anos de escassez de chuva no restante do estado. Um comportamento semelhante ocorre no posto de Trairi, este é beneficiado pela proximidade da costa e tem as maiores precipitações dentre os quatro postos. O posto localizado em Uruburetama se localiza sobre a serra e devido à barreira natural também tem pluviometria acentuada em relação aos demais. Uma exceção ocorre no posto de Tururu, localizado na sede do Município que apresenta uma média pluviométrica anual baixa em relação aos demais postos, fato este motivado por sua localização com características de áreas típicas do sertão.

Tabela 2 - Caracterização dos postos pluviométricos.

\begin{tabular}{|l|l|l|l|l|}
\hline Posto/Localização/Município & Latitude & Longitude & \multicolumn{1}{|c|}{ Média } & Desvio padrão \\
\hline Itapipoca & -3.4982 & -39.5766 & $1069,5 \mathrm{~mm}$ & $372,72 \mathrm{~mm}$ \\
\hline Uruburetama & -3.6326 & -39.4933 & $1014,1 \mathrm{~mm}$ & $396,46 \mathrm{~mm}$ \\
\hline Tururu & -3.5978 & -39.4933 & $849,7 \mathrm{~mm}$ & $363,42 \mathrm{~mm}$ \\
\hline Trairi & -3.2764 & -39.2661 & $1164,4 \mathrm{~mm}$ & $415,40 \mathrm{~mm}$ \\
\hline
\end{tabular}

\section{Análise dos Dados Coletados nos Postos Pluviométricos}

Foi realizada análise estatística para os cálculos da média e do desvio padrão para todos os postos pluviométricos. Tanto as precipitações de cada posto pluviométrico, quanto os totais pluviométricas da bacia foram analisados. Para o cálculo da média utilizou-se a seguinte equação.

$$
\text { Média: } \bar{x}=\frac{\sum x_{i}}{n}
$$

em que $\bar{x}$ é o valor médio da amostra, $\sum x_{i}$ é a somatória de todos os dados da amostra e n é o número de dados amostrais.

A média é um bom parâmetro para considerar anos secos e anos úmidos e é bastante estável para séries acima de 30 anos, esse procedimento metodológico é recomendado pela Organização Meteorológica Mundial (OMM), que estabeleceu esta periodicidade como padrão para as normais climáticas (Reboita e Kruche, 2018).

O desvio padrão, é um parâmetro de dispersão, levando o analista a entender como os dados numéricos se distribuem em torno de um valor da tendência central. O desvio padrão é o parâmetro de dispersão mais utilizado tanto em hidrologia quanto em outros campos. O mesmo pode ser calculado de acordo com a equação seguinte:

Desvio padrão: $\mathrm{s}=\sqrt{\frac{\sum\left(x_{i-\bar{x}}\right)^{2}}{n-1}}$

Em que, $s$ é o desvio padrão da amostra e $\bar{x}$ é o valor médio dos dados da amostra.

Além da análise da série total de 42 anos de precipitações da região, foram analisadas através de gráficos, medias moveis por períodos de 10 anos para as séries, e para a série regional, com intuito de observar interações entre períodos de baixa precipitação e as oscilações de temperatura no Oceano Pacífico: El Nino e La Nina.

A análise de anomalias de chuvas foi calculada segundo o método IAC (Índice de Anomalias de Chuvas). Para (Sanches et al., 2014), o IAC avalia o grau de severidade de anos secos e a intensidade de umidade nos períodos de chuva.

Foram utilizados como ferramentas para os cálculos estatísticos os softwares Excel, 
programa R e o programa SPSS (Statistical Package for Social Sciences), versão 19.

\section{Avaliação da Presença de Tendência}

Após a montagem das séries temporais de cada posto pluviométrico e das precipitações anuais acumuladas na área da Bacia foram aplicados testes estatísticos para avaliar a presença de tendências nas precipitações da região. Os testes aplicados para este fim foram os paramétricos de Man-Kendall e Spearmans's Rho e de regressão linear que é não paramétrico.

\section{Teste de Man-Kendall}

Pesquisas indicam que este teste é o mais indicado para análise de mudanças climáticas pois indica o ponto aproximados do início de uma tendência (Costa et al., 2015). De acordo com o teste de Man-Kendall os valores obtidos a partir da série estudada foram reagrupados de acordo com sua ordem em (x1, x2, x3 ... xn) sendo o (x1) valor inicial e o (xn) o valor final. Para aplicação deste teste utiliza-se a equação (03):

$S=\sum_{i=1}^{n-1}\left(\sum_{j=i+1}^{n} \operatorname{sgn}(R i-R j)\right.$

Em que:

$\operatorname{sgn}(x)=1$ para $X>0$

$\operatorname{sgn}(x)=0$ para $X=1$

$\operatorname{sgn}(x)=-1$ para $X<1$

Se $(H 0)$ hipótese nula for verdadeira então $S$ é aproximadamente distribuído por:

$u=0 ; \sigma=n(n-1)(2 n=5) 18$

A estatística $Z$ é, portanto: $Z=|S| \sqrt{\sigma}$.

\section{Teste de Spearman's Rho}

O teste de Searman's Rho mede a intensidade de correlação entre duas variáveis, no caso de análise de tendência em séries temporais pluviométricas considera-se a variável tempo representado por cada ano da série e a variável precipitação. Assim como no teste de Mann Kendall, os valores são reorganizados e o teste estatísticos "ps" é o coeficiente de correlação representado pela equação (04):

$$
p s=\frac{S x y}{\sqrt{S x S y}}
$$

$$
\begin{aligned}
& S x=\sum_{i=1}^{n}(x i-\bar{X})^{2} \\
& S Y=\sum_{i=1}^{n}(y i-\bar{Y})^{2} \\
& S X Y=\sum_{i=1}^{n}(x i-\bar{X})(y i-\bar{Y})
\end{aligned}
$$

Em que xi representa o tempo yi representa a variável de interesse que são as precipitações, $\bar{X}$ e $\bar{Y}$ representam as médias xi e yi. Tanto em Spearman's Rho quanto em Mann Kendall a hipótese nula $(H 0)$ representa ausência de tendência e valores positivos representam tendência positivas e valores negativos representam tendências negativas.

\section{Teste de Regressão Linear}

O teste de regressão linear é um teste paramétrico que consiste em verificar se há uma tendência linear examinando a relação entre o tempo (x) e uma variável de interesse (y), o teste é realizado através da equação:

\section{$\mathrm{b}=\sum(\boldsymbol{x} \boldsymbol{i}-\overline{\mathbf{X}}) \boldsymbol{n} \boldsymbol{i}=\mathbf{1}(\boldsymbol{y} \boldsymbol{i}-\overline{\boldsymbol{Y}}) \sum(\boldsymbol{x} \boldsymbol{i} \mathbf{n} \mathrm{I}=\mathbf{1}-\mathrm{X})^{\mathbf{2}}$}

O intercepto é estimado como:

$\mathrm{a}=\overline{Y-} \mathrm{b} \bar{X}$

Os testes foram realizados utilizando o pacote estatístico SPSS (Statistical Package for Social Sciences) na versão 19 , o mesmo é uma ferramenta estatística utilizado mundialmente que emprega técnicas estatísticas básicas e avançada.

\section{Análise de Anomalias de Precipitações Através do IAC}

Para avaliação interanual das anomalias pluviométricas foi utilizado o IAC - Índice de Anomalias de Chuvas. Pela análise do IAC foi possível avaliar tanto a frequência com que ocorrem anos secos e anos úmidos, quanto à severidade do evento e sua variabilidade espacial e temporal, (Sanches et al., 2014; Noronha et al, 2015).

O IAC foi desenvolvido por ROOY em 1965, e adaptado para a região semiárida nordestina, (Moraes e Nery, 2014). Para se chegar ao IAC utilizou-se a equação seguinte:

$$
\begin{aligned}
& \text { IAC }=3\left[\frac{N-\bar{N}}{\bar{M}-\bar{N}}\right]-\text { Para anomalias positivas; } \\
& \text { IAC }=-3\left[\frac{N-\bar{N}}{\bar{X}-\bar{N}}\right]-\text { Para anomalias negativas. }
\end{aligned}
$$

Em que $\mathrm{N}$ - precipitação do mês ou ano que será gerado o IAC.

Nunes, F. T., Vasconcelos Júnior, F. C., Silveira, C. S. 
$\bar{N}$ - Precipitação média mensal ou anual da série histórica construída.

$\bar{M}$ - Média mensal ou anual das dez maiores precipitações da série histórica.

$\bar{X}$ - Média mensal ou anual das dez menores precipitações da série histórica.

Consideram-se anomalias positivas as chuvas acima da média histórica obtida a partir da análise dos dados de precipitações das séries pluviométrica, e as anomalias negativas como sendo as chuvas abaixo da média histórica.

Seguindo a metodologia utilizada por (Moraes e Nery, 2014; Sanches et al., 2015) cada ano foi classificado de acordo com intensidade de umidade e/ou severidade de escassez de chuva.

Para classificar a normalidade ou anormalidade pluviométrica na área da Bacia do Mundaú foi calculado o IAC, de acordo com a média pluviométrica anual, de todos os anos da série histórica e distribuídos de acordo com a (Tabela 3).

Tabela 3 - Classificação dos anos úmidos e secos na Bacia do Rio Mundaú (IAC).

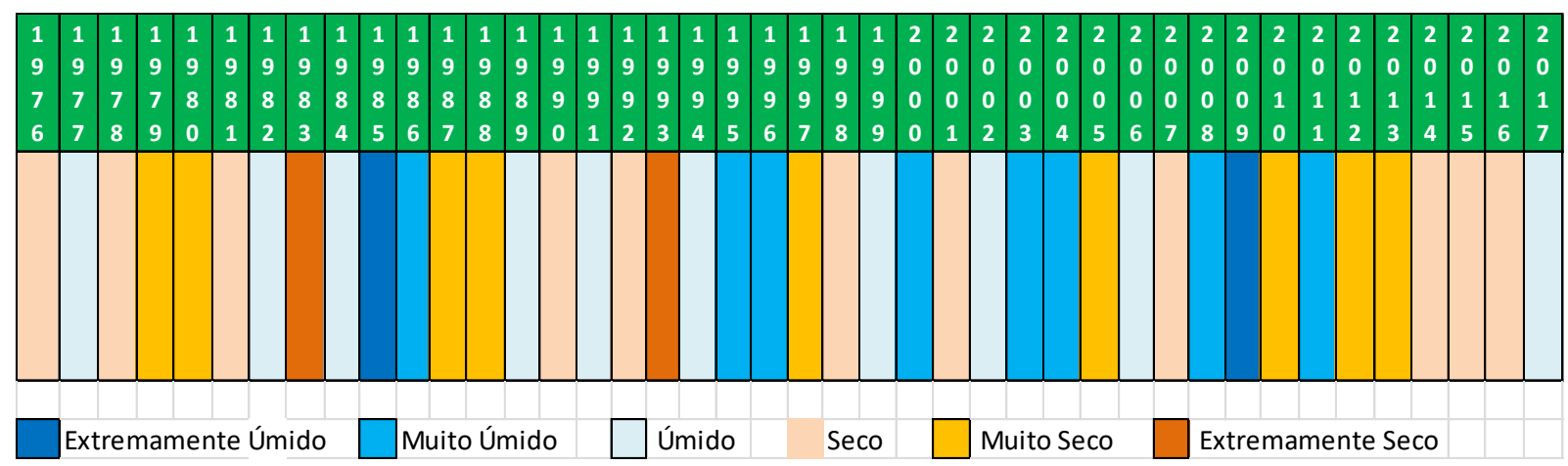

\section{Relação das Anomalias de chuvas da Bacia do Mundaú com os Fenômenos El Nino e La Nina}

Para avaliar a possível influência dos fenômenos El Nino e La Nina no regime de precipitações da Bacia hidrográfica do Rio Mundaú foi elaborado um levantamento das oscilações de temperatura do Oceano Pacífico, representado através da (tabela 4). Os anos foram agrupados para facilitar a visualização das oscilações de temperatura do pacífico de forma o possibilitar e relacionar estas oscilações com as anomalias de chuvas da região.

Neste caso a relação entre anomalias de chuvas e anomalias da temperatura do Oceano Pacífico foi feita dos meses que antecede e durante a quadra chuvosa na Bacia do Rio Mundaú, que ocorre de fevereiro a maio, com maior intensidade em março e abril.

Tabela 4 - Anos de predomínio de El Nino/La Nina e neutralidade.

\begin{tabular}{|c|c|c|c|c|c|c|c|c|c|c|c|c|c|c|c|c|c|c|c|c|c|c|c|c|c|}
\hline \multirow{3}{*}{$\begin{array}{l}\text { Ocorrências } \\
\text { (Histórico) }\end{array}$} & \multicolumn{25}{|c|}{ Período de El Nino e La Nina } \\
\hline & \multicolumn{12}{|c|}{ Ano 1} & \multicolumn{13}{|c|}{ Ano 2} \\
\hline & $\mathbf{J}$ & $\mathbf{F}$ & $\mathbf{M}$ & $\mathbf{A}$ & M & & $\mathbf{J}$ & A & $\mathbf{S}$ & C & $\mathbf{N}$ & I & & $\mathbf{J}$ & $\mathbf{F}$ & $\mathbf{M}$ & $\mathbf{A}$ & $\mathbf{M} \mathbf{J}$ & $\mathbf{J}$ & A & & S & $\mathbf{O}$ & $\mathbf{N}$ & $\mathbf{D}$ \\
\hline $1972-1973$ & & & & & & & & & & & & & & & & & & & & & & & & & \\
\hline $1974-1975$ & & & & & & & & & & & & & & & & & & & & & & & & & \\
\hline $1976-1977$ & & & & & & & & & & & & & & & & & & & & & & & & & \\
\hline $1978-1979$ & & & & & & & & & & & & & & & & & & & & & & & & & \\
\hline $1980-1981$ & & & & & & & & & & & & & & & & & & & & & & & & & \\
\hline $1982-1983$ & & & & & & & & & & & & & & & & & & & & & & & & & \\
\hline $1984-1985$ & & & & & & & & & & & & & & & & & & & & & & & & & \\
\hline $1986-1987$ & & & & & & & & & & & & & & & & & & & & & & & & & \\
\hline $1988-1989$ & & & & & & & & & & & & & & & & & & & & & & & & & \\
\hline
\end{tabular}




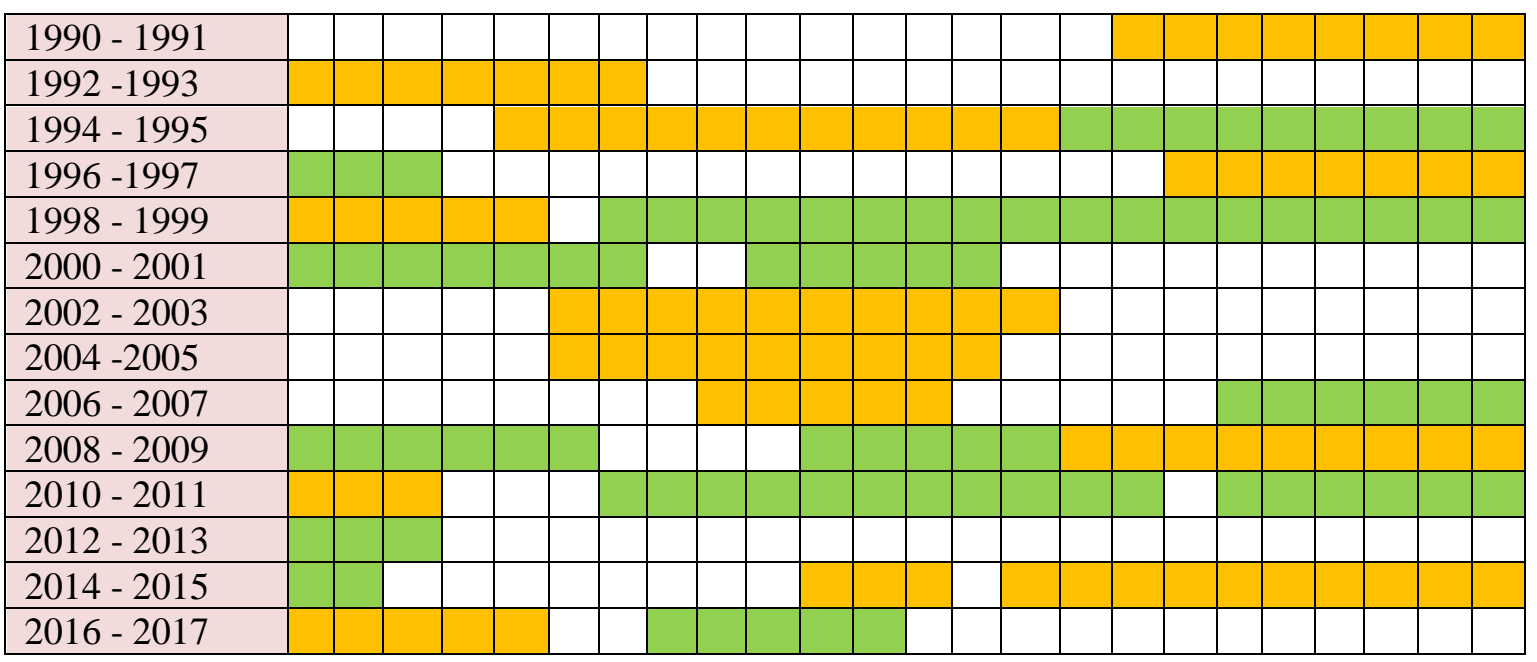

\section{Resultados da discussão}

Avaliações de Tendências e Correlação
Tanto em Kendall Tau quanto no teste de Spearman's rho se evidenciaram uma correlação direta entre os postos e os totais pluviométricos na Bacia do Rio Mundaú para a série de 1976 a 2017.

Tabela 5 - Correlação de precipitações entre os postos pluviométricos e Bacia do Rio Mundaú.

\begin{tabular}{|l|l|l|l|l|}
\hline \multirow{2}{*}{ Postos } & \multicolumn{2}{c|}{ Kendall's tau } & \multicolumn{2}{c|}{ Spearmans rho } \\
\cline { 2 - 5 } & Coefic. de correlação & P - valor & Coefic. de correlação & p - valor \\
\hline Itapipoca & 0,772 & 0,00 & 0,900 & 0,00 \\
\hline Trairi & 0,584 & 0,00 & 0,787 & 0,00 \\
\hline Uruburetama & 0,676 & 0,00 & 0,858 & 0,00 \\
\hline Tururu & 0,543 & 0,00 & 0,748 & 0,00 \\
\hline
\end{tabular}

Os testes foram concordantes, o valor de $\mathrm{p}$ (p-valor) observado na (tabela 5) zerou nos dois testes, neste caso adota-se a hipótese alternativa, isso evidencia uma significativa correlação positiva entre as variáveis envolvidas. $\mathrm{O}$ coeficiente de correlação conforme a (tabela 5) mostra que o posto de Itapipoca apresenta uma forte correlação com as precipitações da bacia em Kendall's tau, já a correlação de Spearmans' rho todos os postos apresentam forte correlação.

No teste de regressão Linear verifica-se que os postos localizados em Itapipoca e Trairi apresentam uma significativa regressão indicando que os dois postos pluviométrico são os que têm uma maior influência no aporte de chuvas para a bacia. O teste indica ainda um maior valor de "beta" para o posto de Itapipoca apontando que este é o que apresenta maior influência pluviométrica para a Bacia em análise.

O resultado da avaliação de tendências na área de abrangência da Bacia do Rio Mundaú não apresentou tendências negativas de precipitações como indica a (Figura 2) gerado a partir da análise estatística da série pluviométrica avaliada. Foi observada uma tendência positiva moderada nas precipitações da bacia analisada. 


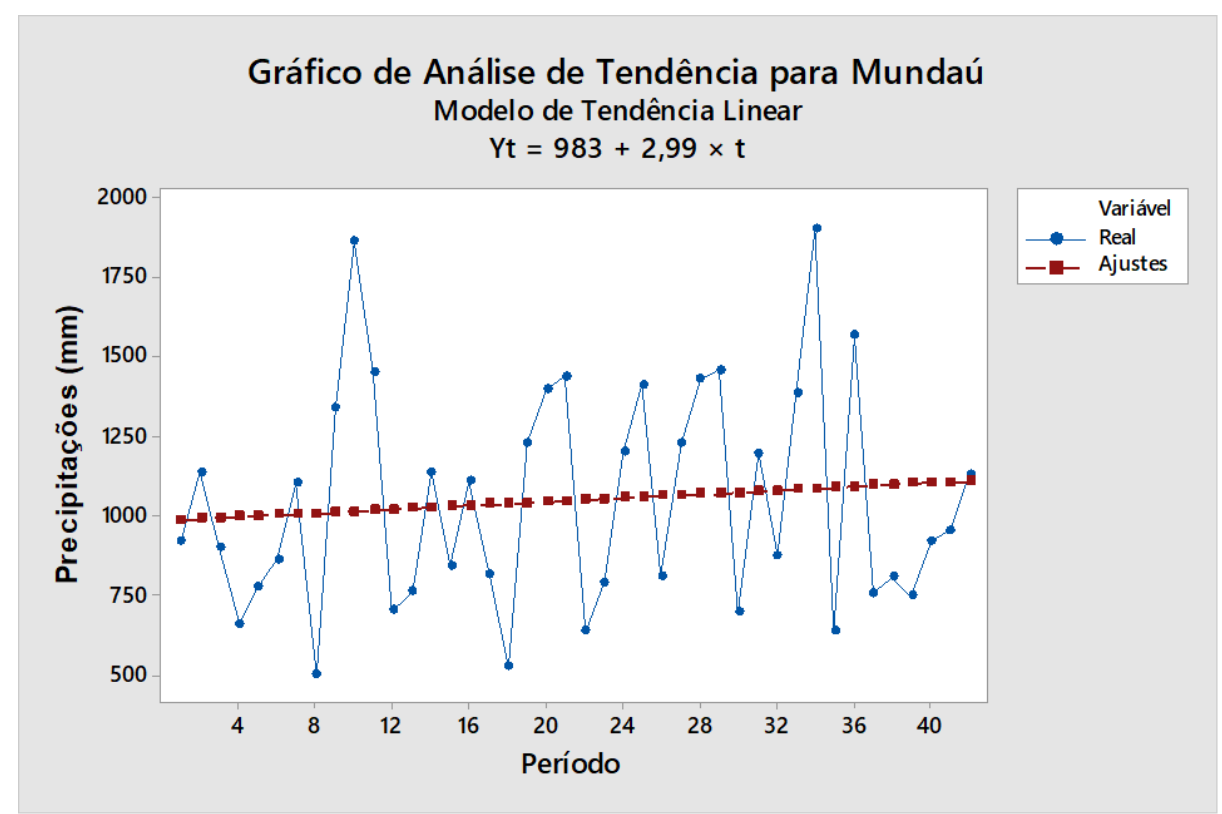

Figura 2 - Tendência de precipitação na bacia do Rio Mundaú.

Foi realizada uma avaliação de tendências em cada posto pluviométrico, como mostra a (Figura 2). O resultado da análise de tendências de precipitações na área de cada posto mostra que os Municípios de Uruburetama e Tururu apresentam tendências de redução de precipitações, enquanto que Itapipoca e Uruburetama apresentaram leve tendência de elevação nos acumulados de chuvas.

Um aspecto relevante observado através dos testes de tendência, representados pelos na (Figura 3), foi que a severidade do período de seca dos últimos cinco anos da série, afetou bem mais os municípios com tendências negativas de precipitações como no caso de Uruburetama e Tururu.

\section{Resultados da Análise das Anomalias de Chuva IAC}

De posse da média pluviométrica da Bacia e de cada posto pluviométrico utilizado, foi calculado o Índice de Anomalia de Chuvas (IAC) de cada ano da série estudada para avaliar a intensidade das estações chuvosas e das estações secas na Bacia do Rio Mundaú bem como sua variabilidade ao longo do tempo. A partir dos cálculos do IAC foram gerados gráficos e tabelas para facilitar a compreensão dos dados, através da (Figura 4) observa-se a variação do índice ao longo de 42 anos da série estudada.

A análise do gráfico mostra que os anos com anomalias negativas de chuvas foram predominantes na Região com 52,4\% de incidência, sendo $26,2 \%$ da média de precipitações dos anos estudados considerados secos (S), outros $21,4 \%$ dos anos da série foram considerados muito secos (MS) enquanto $4,8 \%$ foram considerados extremamente secos (ES). Já os anos com chuvas normais ou acima da média, 23,8\% foram considerados úmidos ou chuvosos (U), $19 \%$ foram considerados muito úmidos (MU) enquanto que $4,8 \%$ dos anos da série foram considerados.

Analisando as anomalias pluviométricas separados em períodos de dez anos verificou-se que a primeira e a última década da série estudada apresentaram o maior índice de anomalias negativas. No período de 1976 a 1985 foi observado que $60 \%$ dos anos tiveram chuvas abaixo da média, dos quais dois anos foram considerados muito secos e um ano foi considera extremamente seco. Na última década, de 2007 a 2016 observou-se o maior índice de anomalias negativas de chuvas com $70 \%$ dos anos de chuvas abaixo da média, destes, três anos foram considerados muito secos e quatro anos foram considerados secos, o período de 2012 a 2016 foi o mais seco da série estudada com cinco anos de secas ininterruptos, o prolongamento desse período de secas contribuiu para tornar a escassez de chuva ainda mais severa na região.

Através do cálculo do IAC de cada posto pluviométrico foi possível avaliar as anomalias de chuvas em cada Município que faz parte da bacia em estudo, o mesmo está representado através da (Figura 5). 
Figura 3 - Verificação de tendência regionalizada em cada posto pluviométrico

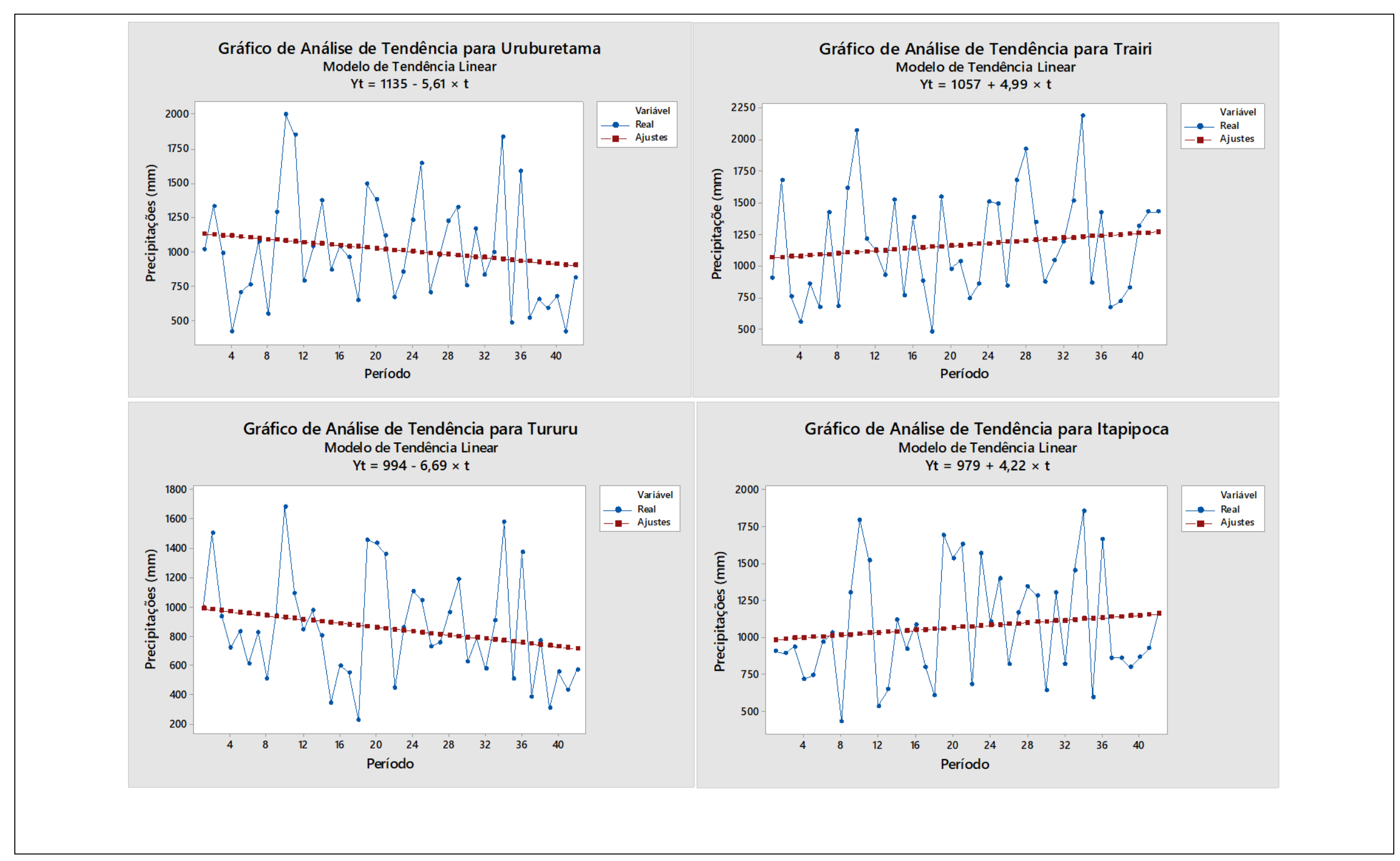




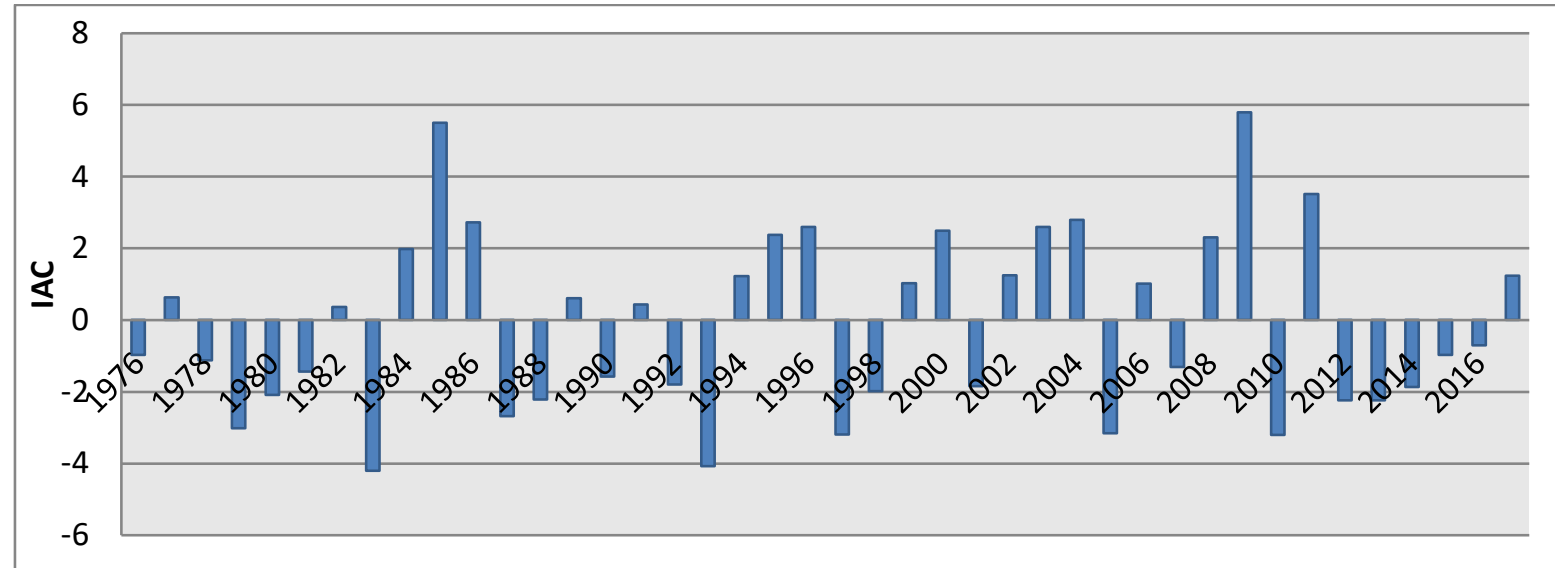

Figura 4 - IAC para a Bacia Hidrográfica do Rio Mundaú.
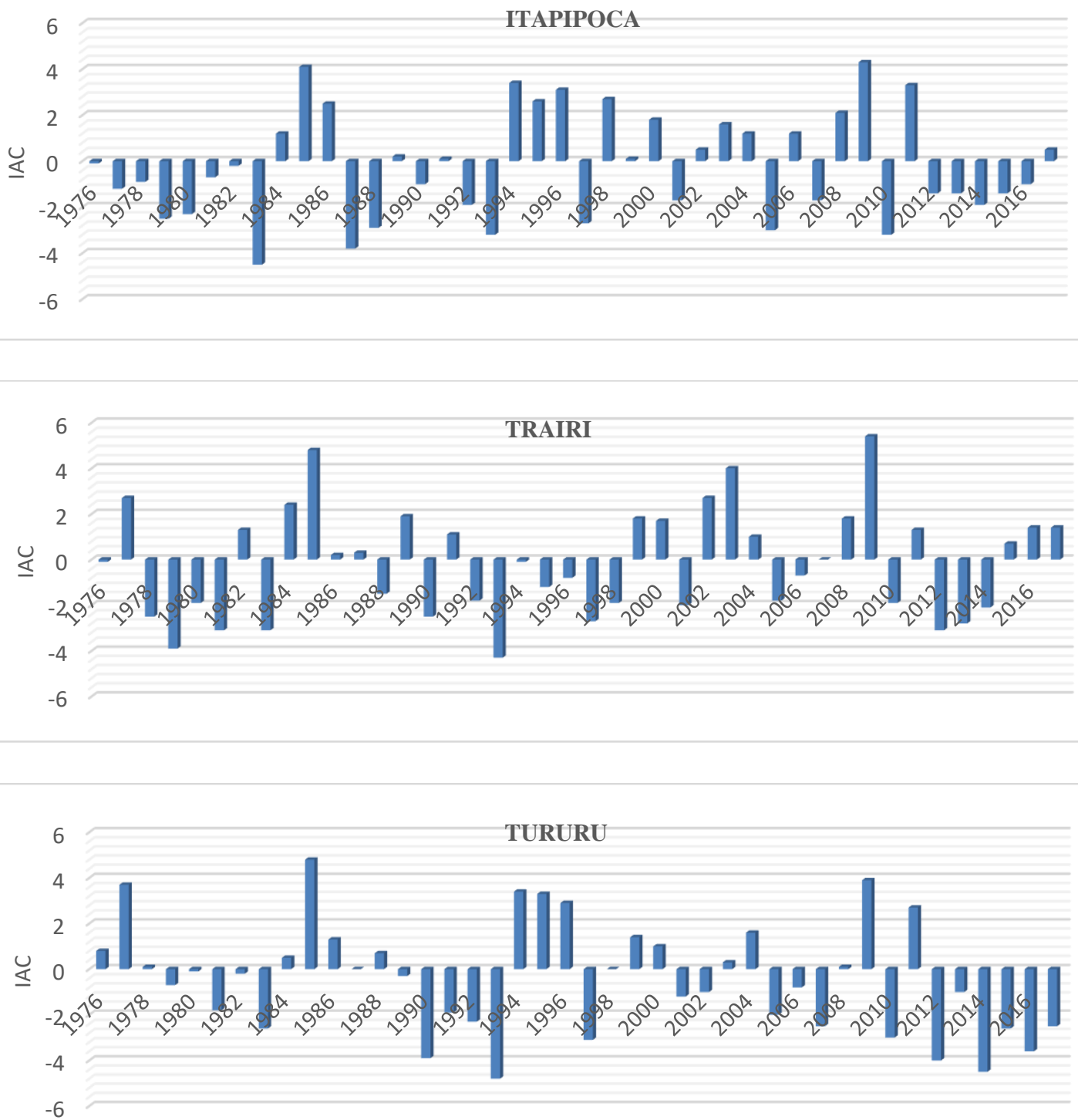


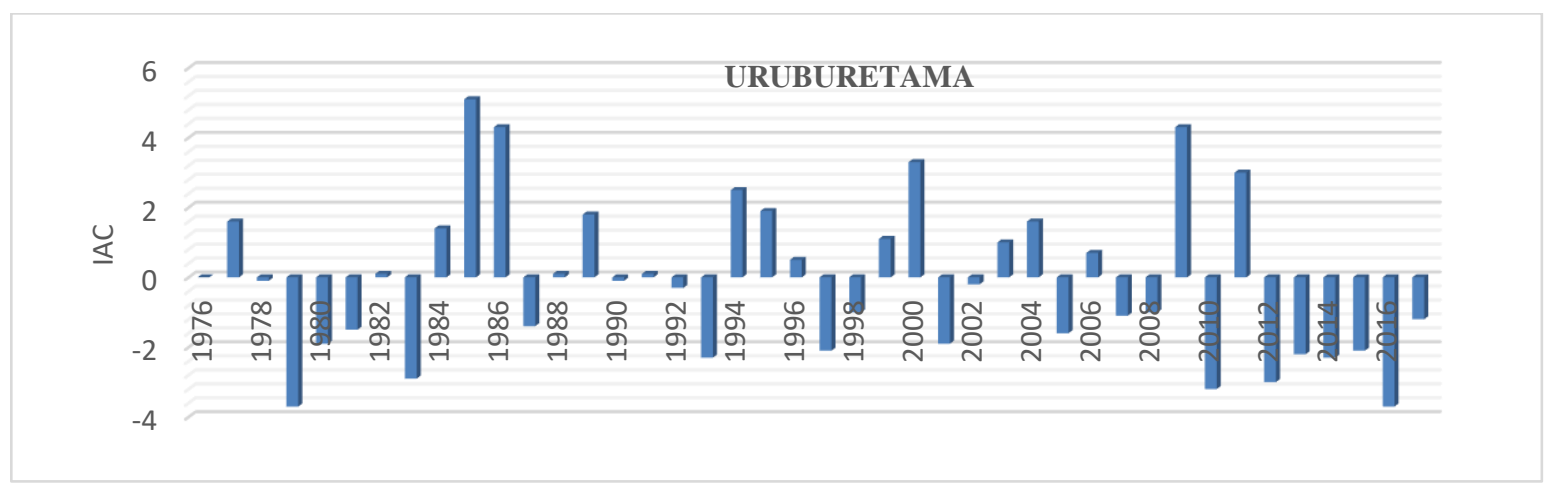

Figura 5 - Series temporais de IAC anual por posto pluviométrico em cada município.

A pluviosidade dos Municípios que fazem parte da Bacia analisada apresenta uma grande homogeneidade, com exceção dos Municípios de Tururu, cuja pluviosidade é bem mais baixa que os demais, este fato é observado através das médias pluviométricas de cada um deles. Através da análise do IAC de cada Município, pode se observar que a última grande seca que atingiu o Semiárido brasileiro, afetou os Municípios de Uruburetama e Tururu com maior intensidade que Itapipoca e Trairi.

Através da (Tabela 6) é possível verificar uma redução de anos com anomalias positivas de chuvas e aumento dos casos de secas em todos os postos pluviométricos estudados. Em Itapipoca ocorreu redução em média de 4 para 2 ano por década nos casos de anos úmidos, e elevação de dois para seis anos nos casos de anos secos. O mesmo ocorreu em Uruburetama reduzindo a quantidade de anos úmidos de uma média de três para apenas um ano, e elevando os casos de anos muito secos de uma média de um ano para seis anos. No Município de Tururu houve a redução de anos úmidos de uma média de três anos por década para apenas um ano, ocorreu ainda a elevação nos casos de anos muito secos de uma média de um ano por década para quatro anos. Os casos de anos extremamente secos em Tururu nas três primeiras décadas da série ocorreram apenas um caso, porém nos últimos doze anos ocorreram três casos. Todas essas ocorrências foram desencadeadas, sobretudo nos últimos doze anos.

Tabela 6 - Classificação quantitativa de anomalias de chuvas. EU (extremamente úmido), UM (muito úmido), U (úmido), S (seco), MS (muito seco) e ES (extremamente seco). 


\begin{tabular}{|c|c|c|c|c|c|c|c|c|}
\hline & \multicolumn{2}{|c|}{$1976-1985$} & \multicolumn{2}{|c|}{$1986-1995$} & \multicolumn{2}{|c|}{$1996-2005$} & \multicolumn{2}{|c|}{2006 - 2017} \\
\hline \multirow[t]{7}{*}{ Itapipoca } & EU & 1 & $\mathrm{EU}$ & 0 & EU & 0 & EU & 1 \\
\hline & MU & 0 & MU & 3 & MU & 2 & ML & 1 \\
\hline & $\mathrm{U}$ & 5 & $\mathrm{U}$ & 2 & $\mathrm{U}$ & 5 & $\mathrm{U}$ & 2 \\
\hline & \multicolumn{2}{|c|}{ NORMAL 0} & \multicolumn{2}{|c|}{ NORMAL 0} & \multicolumn{2}{|c|}{ NORMA 0} & \multicolumn{2}{|c|}{ NORMAL 0} \\
\hline & $S$ & 1 & $S$ & 2 & $S$ & 1 & $S$ & 6 \\
\hline & MS & 3 & MS & 3 & MS & 2 & MS & 2 \\
\hline & ES & 1 & ES & 0 & ES & 0 & ES & 0 \\
\hline \multirow[t]{7}{*}{ Uruburetama } & EU & 1 & EU & 1 & EU & 0 & EU & 1 \\
\hline & MU & 1 & MU & 1 & MU & 2 & ML & 1 \\
\hline & $\mathrm{U}$ & 3 & $\mathrm{U}$ & 4 & $\mathrm{U}$ & 3 & $\mathrm{U}$ & 1 \\
\hline & \multicolumn{2}{|c|}{ NORMAL 1} & \multicolumn{2}{|c|}{ NORMAL 0} & \multicolumn{2}{|c|}{ NORMAL 0} & \multicolumn{2}{|c|}{ NORMAL 0} \\
\hline & $S$ & 3 & $S$ & 3 & $\mathrm{~S}$ & 4 & $S$ & 3 \\
\hline & MS & 1 & $\mathrm{MS}$ & 1 & MS & 1 & MS & 6 \\
\hline & ES & 0 & ES & 0 & ES & 0 & $\mathrm{ES}$ & 0 \\
\hline \multirow[t]{7}{*}{ Trairi } & EU & 1 & EU & 0 & EU & 1 & EU & 1 \\
\hline & MU & 2 & MU & 0 & MU & 1 & ML & 0 \\
\hline & $\mathrm{U}$ & 1 & $\mathrm{U}$ & 4 & $\mathrm{U}$ & 3 & $\mathrm{U}$ & 5 \\
\hline & \multicolumn{2}{|c|}{ NORMAL 0} & \multicolumn{2}{|c|}{ NORMAL 0} & \multicolumn{2}{|c|}{ NORMAL 0} & \multicolumn{2}{|c|}{ NORMAL 1} \\
\hline & $S$ & 2 & $S$ & 4 & $S$ & 5 & $S$ & 2 \\
\hline & MS & 4 & MS & 1 & MS & 0 & $\mathrm{MS}$ & 3 \\
\hline & $\mathrm{ES}$ & 0 & $\mathrm{ES}$ & 1 & ES & 0 & ES & 0 \\
\hline \multirow[t]{5}{*}{ Tururu } & EU & 1 & $\mathrm{EU}$ & 0 & EU & 0 & $\mathrm{EU}$ & 0 \\
\hline & $\mathrm{MU}$ & 1 & MU & 2 & MU & 1 & ML & 2 \\
\hline & $\mathrm{U}$ & 3 & $\mathrm{U}$ & 3 & $\mathrm{U}$ & 3 & $\mathrm{U}$ & 1 \\
\hline & \multicolumn{2}{|c|}{ NORMAL 0} & \multicolumn{2}{|c|}{ NORMAL 1} & \multicolumn{2}{|c|}{ NORMAL 1} & \multicolumn{2}{|c|}{ NORMA 0} \\
\hline & $S$ & 4 & $S$ & 1 & $S$ & 4 & $S$ & 2 \\
\hline
\end{tabular}




\section{Relação das Anomalias de Chuvas com o Fenômeno El Nino}

A (Figura 6) representa a relação das anomalias de chuvas da Bacia do Rio Mundaú com os eventos El Nino e La Nina. Foi verificado que na série histórica correram 22 anos de chuvas abaixo da média e 20 anos com chuvas dentro e acima da média.

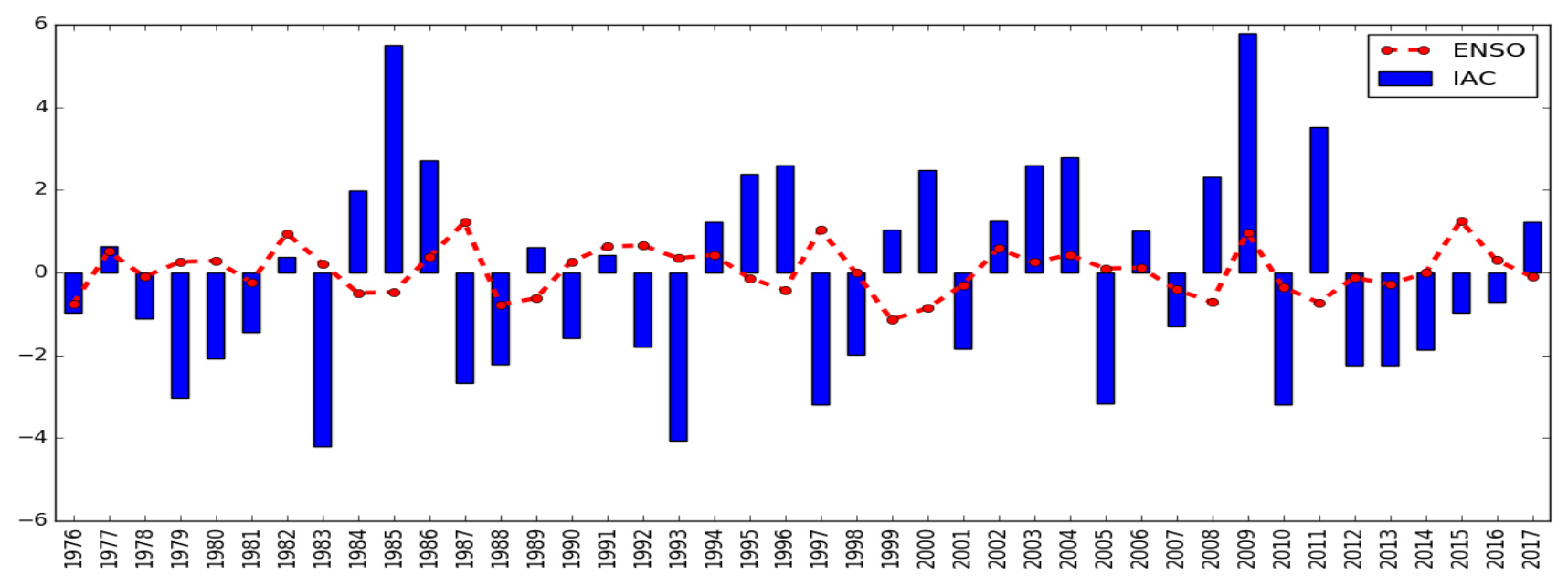

Figura 6 - Relação de Anomalias de Chuvas da Bacia do Rio Mundaú com Anomalias de Temperatura do Pacífico - ENOS.

Para melhor compreender a relação do fenômeno ENOS com anomalias de chuvas na Região da Bacia do Rio Mundaú é preciso analisar os meses do ano em que ocorreram anomalias positivas do ENOS, visto que a estação das chuvas da Região predomina de fevereiro a maio, desta forma se o fenômeno ocorreu no segundo semestres do ano o reflexo nas precipitações da bacia vai ocorrer no inicio do ano seguinte coincidindo com o período de chuvas, considera-se ainda que ano que predomina o ENOS poderá ocorrer meses do ano de neutralidade ou até de TSM negativa.

Em primeiro lugar, os resultados corroboram que o ENOS exerce uma forte influência sobre o período chuvoso da Bacia do Rio Mundaú do ano seguinte ao início do evento, especialmente quando a TSM positiva ocorrer no último semestre. Para comprovar isso se observa a figura 4, o ano de 1978 teve anomalias negativas de chuvas mesmo sem ocorrência do ENOS, no entanto ele prevaleceu nos últimos meses de 1977 e no primeiro mês do referido ano. Isso se repete nas anomalias negativas de chuvas nos anos de 1983, 1988, 1991, 1992, 1998 e 2007.

Em segundo lugar considera-se que o ENOS não é o único fenômeno causador ou inibidor de chuvas na região, para (Alves et al., 2016), existe uma associação entre a variabilidade interanual de chuvas do Nordeste com TSM do Atlântico Tropical, além da interação oceanoatmosfera influenciar a circulação atmosférica na área do atlântico mencionada.

Observando a relação das precipitações com as anomalias de temperatura do Oceano Pacífico verificou-se que as anomalias positivas de chuvas, no caso os anos dentro e acima da média histórica $47,3 \%$ dos anos estavam sobre a influência do La Nina, $42,1 \%$ dos casos ocorreram em anos de neutralidade e 10,5\% ocorreram em anos de El Nino.

No caso de anomalias negativas de precipitações na área de Bacia do Mundaú, as chuvas abaixo da média 45,4\% dos casos ocorreram em anos sobre a influência do El Nino, enquanto que outros $40,9 \%$ das ocorrências se deram em anos de neutralidade e 13,6\% das chuvas abaixo da média ocorreram em anos de La Nina.

A tabela 6 mostra a distribuição em porcentagem dos anos secos e úmidos relacionados aos eventos El Nino La Nina e de neutralidade na área de abrangências da Bacia do Mundaú. 
Tabela 7 - Influência de anomalias na temperatura do Oceano Pacífico no comportamento anual das chuvas na Bacia do Rio Mundaú.

\begin{tabular}{|l|l|l|l|l|l|l|l|l|}
\hline \multicolumn{3}{|c|}{ Úmido } & \multicolumn{3}{c|}{ Muito úmido } & \multicolumn{3}{c|}{ Extremamente úmido } \\
\hline El Nino & Neutro & La Nina & El Nino & Neutro & La Nina & El Nino & Neutro & La Nina \\
\hline $11,1 \%$ & $66,6 \%$ & $22,2 \%$ & $12,5 \%$ & $25 \%$ & $62,5 \%$ & - & - & $100 \%$ \\
\hline
\end{tabular}

\begin{tabular}{|l|l|l|l|l|l|l|l|l|}
\hline \multicolumn{3}{|c|}{ Seco } & \multicolumn{3}{c|}{ Muito seco } & \multicolumn{3}{c|}{ Extremamente seco } \\
\hline El Nino & Neutro & La Nina & El Nino & Neutro & La Nina & El Nino & Neutro & La Nina \\
\hline $44,4 \%$ & $36,3 \%$ & $18,1 \%$ & $44,4 \%$ & $44,4 \%$ & $11,1 \%$ & $50 \%$ & $50 \%$ & - \\
\hline
\end{tabular}

\section{Conclusões}

Verificou-se que a média pluviométrica da Bacia do Rio Mundaú tem se mantido dentro de um padrão com algumas variações decenais que não indicam diretamente alterações nos índices de chuvas ao longo do tempo. A média pluviométrica regional apresenta-se acima da média observada no contexto geral do Semiárido nordestino e do estado do Ceará.

Levando em consideração as precipitações da bacia de forma geral não foi verificado tendências de redução de precipitações ao longo do tempo estudado, no entanto observou-se que os postos de Tururu e Uruburetama apresentaram tendências à redução de precipitações, enquanto nos posto de Itapipoca e Trairi observou-se tendência positiva de precipitações.

Os testes de Kendall Tau e Spearman's Rho comprovaram uma grande correlação entre o aporte pluviométrico da bacia e os postos de Itapipoca e Trairi, mostrando que os dois apresentaram uma maior contribuição pluviométrica para bacia em análise, resultado da localização geográfica dos dois postos. Os postos de Uruburetama e Tururu são muito próximos mais apresentam acentuada diferença de precipitações, resultante da localização em área de serra, no caso de Uruburetama e de sertão no caso de Tururu, esses dois postos apresentaram tendências de redução de chuvas de acordo com os testes realizados.

Mesmo a localização geográfica dos quatro postos não apresentarem grande distância, observou-se a presença de microclimas com uma diferença significativa de precipitação na área da bacia, esta ocorrência foi verificada principalmente no posto localizado no município de Tururu, cuja precipitação foi a mais reduzida em comparação aos outros postos se equiparando com as demais áreas semiáridas, por sua vez o posto localizado em Trairi apresentou precipitação mais elevada, resultante da localização próximo da costa do litoral norte do Ceará. Dessa forma apesar da pequena extensão territorial da bacia existe uma significativa heterogeneidade no ponto de vista geográfico e climático.

Através da avaliação do IAC verificou-se uma grande variabilidade de anomalias pluviométricas com alternâncias de anos com umidades acima da média e anos secos. Essa alternância apresenta uma leve predominância de período com anomalias de chuvas abaixo da média histórica, chamando atenção para os últimos seis anos da série estudada que foi o período de anomalias negativas de chuvas mais longo visualizado na série.

A análise quantitativa anual mostra que existem alterações ao longo dos 42 anos nas quantidades de anos úmidos e secos em cada posto pluviométrico estudado, sendo esta a mudança mais significativa observada na avaliação das séries históricas. Analisando as anomalias de chuvas através do IAC observou-se essas alterações indicando que está se elevando o número de anos secos com redução de anos úmidos em um grau de intensidade maior ou menor dependendo do posto observado. Uruburetama e Tururu são os postos com maiores evidências desta ocorrência.

Não se evidenciou a existência de alterações no padrão climático ao longo da série, no entanto $o$ estudo do IAC evidenciou uma significativa variabilidade temporal e espacial nas precipitações da bacia e intensificação dessa variabilidade na última década, observou-se que o ENOS influência de forma significativa a ocorrência de anomalias negativas de chuvas. Anos secos e muitos secos ocorreram com um percentual de 44,4\% sobre a influência do El Nino, no entanto entre os anos com chuvas dentro da média apenas $11,1 \%$ dos casos estiveram sobre a influência do El Nino, de acordo com a média histórica da Região. 


\section{Referências}

Alves, José M. B., Vasconcelos Jr, Francisco C.; Chaves, Rosane R., Silva, Emerson M., Servain, Jacques, Costa, Alexandre A., Sombra, Sérgio S., Barbosa, Algusto C. B. e Santos, Antonio C. S, 2016. Evaluation of the AR4 CMIP3 and the AR5 CMIP5 Model and Projections for Precipitacions in Northeast Brazil. Frontiers in Earth Science 4, Article 44,

Assis, Janaina Maria Oliveira de, Sousa,Verônica Maria de, Sobral, Maria do Carmo, 2015. Análise Climática da Precipitação do Submédio da Bacia do São Francisco com Base no índice de Anomalias de Chuvas. Revista Brasileira de Ciências Ambientais 36, 115-127.

Chechi, Leonardo, Sanches, Fábio de Oliveira, 2013. O Uso do Índice de Anomalia de Chuva (IAC) na avaliação do Fenômeno do El Niño Oscilação Sul (ENOS) no Alto Uruguai Gaúcho entre 1957-2012. Revista Brasileira de Geografia Fisica 06, 15861597.

Cirilo, José Almir, 2015. Crise Hídrica: Desafios e Superação. Revista USP, $\mathrm{n}^{\circ} .106$ , p. 45-58.

COGERH - Companhia de Gestão dos Recursos Hídricos, 2016: Manual de Operação da Sala de Situação do Ceará. Fortaleza.

Costa, Valdeci José, Ferreira, Matheus, Cordeiro, Marcos Tadeu Andrade, 2015. Análise de Séries temporais Climáticas. Revista de Ciências Agro veterinárias, Lages 4, 169-177.

Cunninghan, Chistopher, Cunha, Ana Paula; Brito, Sheila, Marengo, José, Coutinho Marcos, 2017. Climate Change end Drought in Brasil. Centro Nacional de Monitoramento e Alerta de Desastres Naturais.

Freitas, M. A. V. e Soitos, João Leonardo da Silva, 2014.: Vulnerabilidade, Impactos e Possibilidades de Adaptação da Geração de Energia Hidrelétrica, no Brasil, às Mudanças Climáticas Globais. In: Ribeiro, M. F.; Freitas, Ma. A. V. \& Rosa, L. P.. (Org.). Vulnerabilidade e Ações de Adaptação dos Recursos Hídricos às mudanças Climáticas Globais. 1 ed. Rio de Janeiro: Editora Interciência 3, 1-22.

FUNCEME. Postos Pluviométricos, 2016. Disponível http://www.funceme.br/index.php/areas/23monitoramento/meteorol\%C3\%B3gico/572 -postos-pluviom\%C3\%A9tricos. Acesso: 15. Abr. 2016.

IPCC - Intergorvenmental Panel on Climate Change. Climat Change 2014: Synthesis Report. Contribution of Working Groups I,II end III to the Fifth Assessment Report of the Intergovenmental panel on Climat Change. Edited by R.K. Pachauri em L.A. Meier. Geneva.

IPCC - Intergovernmental Panel on Climate Change. Climate Change 2007: Impacts, Adaptation and Vulnerability. Contribution of Working Group II to the Fourth Assessment Report of the Intergovernmental Panel on Climate Change. Edited by Parry, M.L., O.F. Canziani, J.P. Palutikof, P.J. van der Linden, C.E. Hanson. UK and New York: Cambridge University Press.

Leandro, Carlos Roberto, 2013. Estudo das Consequências do Aquecimento Global na Produção agrícola. Revista On-Line IPOG. $6^{\mathrm{a}}$ Edição $\mathrm{n}^{\circ} 006$.

Marengo, José A., Alves, Lincoln M., Alvala Regina C. S., Cunha, Ana Paula, Brito, Sheila, Moraes, Osvaldo L. L., 2017. Climatic Characteristics of the 2010-2016 Drought in the Semiarid Northeast Brazil Region. Brazilian Academy of Sciences.

Marengo, José A, Cunha, A. P, Alves L.M, 2016. A Seca de 2012-15 no Semiárido do Nordeste do Brasileiro no Contexto Histórico. Revista Climanálise 3, 49-54.

Moraes, Mariana de Paula Costa, Nery, Jonas Teixeira. 2014. Análise da Variabilidade Pluvial na Unidade de Gerenciamento de Recursos Hídricos do Paraíba do Sul. Revista Brasileira de Climatologia 15. 98108

Nóbrega, R. S, Santiago, G. A. C. F., 2014. Tendência de temperatura na superfície do mar nos oceanos Atlântico e Pacífico e variabilidade de precipitação em Pernambuco. Mercator 13, 107-118.

Nóbrega, R. S, Santiago, G. A. C. F.,2015. Tendências do Controle Climático Oceânico Sob a variabilidade Temporal das Precipitações no Nordeste do Brasil. Revista Brasileira de Climatologia 18, 276-292.

Noronha, Gustavo Carneiro de, Hora, Mônica de Aquino Galeano Massera da, Silva, Luciene Pimentel da, 2015. Análise de Anomalia de Chuva Para Microbacia de 
Santa Maria/Cambiocó - RJ. Revista Brasileira de Meteorologia 31, 74-81.

Olivo, Andreia de Menezes, Ishiki, Hamilton Mitsugu, 2014. Brasil Frente à Escassez de àgua. Collóquium Humanarum 11, 41 - 48.

PBMC - Painel Brasileiro de Mudanças Climáticas, 2014. Base Científica das Mudanças Climáticas. Primeiro Relatório de Avaliação Nacional. Volume 1.

Reboita, Michele Simões, Kruche, Nísia, 2018. Normais Climatológicas Provisórias de 1991 a 2010 para Rio Grande, RS. Revista Brasileira de Meteorologia 33, 165-179.

Sanches, Fabio de Oliveira, Verdum, Roberto, Fisch, Gilberto, 2014. O Índice de Anomalias de Chuva (IAC) na Avaliação das Precipitações Anuais de Alegrete RS (1928 - 2009). Caminhos da Geografia 15, 73 - 84.

Santos, Juliana Gonçalves; Ferreira, Vanderlei de Oliveira, 2016. A Variabilidade Pluviométrica na Mesorregião do Triângulo Mineiro/Alto Paranaíba-MG. Geo Textos 12, 233-265.
Santos, Francisco de Amorim dos, Aquino, Cláudia Maria Saboia de, 2017. Análise das precipitações pluviométricas no município de Castelo do Piauí, Nordeste do Brasil. Geousp - Espaço e Tempo (Online) 21, 619633.

Silva, Roberto Omena Barbosa da, Montenegro, Suzana Maria Gico Lima, Sousa, Werônica Meira da, 2017. Tendências de Mudanças Climáticas nas Precipitações Pluviométricas nas Bacias Hidrográficas do Estado de Pernambuco. Eng Sanit Ambient 22, 579589.

Soares, Rogério Barbosa, Campos, Kilmer Coelho, 2013. Uso e Disponibilidade Hídrica No Semiárido do Brasil. Revista da Política Agrícola 3. 48-57.

Travassos, Ibrahim Soares, Sousa, Bartolomeu Israel de, Silva, Aniere Barbosa da, 2013. Secas, Desertificação e Políticas Públicas no Semiárido Nordestino Brasileiro. Revista OKARA: Geografia em debate 7, 147-164. 